\title{
Effect of Breathing Exercise on after pains among Postpartum Women
}

\author{
Dr/ Niven R. Basyouni, Dr/ Isis E. Gohar \\ Assistant professor of Obstetric \& Gynecologic Nursing. Faculty of Nursing-Alexandria University-Egypt. \\ Lecturer of Obstetric \& Gynecologic Nursing. Faculty of Nursing-Alexandria University-Egypt.
}

\begin{abstract}
Background: Puerperium extends between end of placenta delivery and proceeding approximately six weeks. During this period the woman returns back to her pre-pregnant state, preceding many physiological symptoms, most common afterpains.

Objective: This study aims to identify the effect of breathing exercise on afterpains among postpartum women Material and Methods: This quasi-experimental research was conducted in the postpartum ward of the Main Maternity University Hospital, Alexandria-Egypt. A convenient sample of 80 postpartum women meeting the specified inclusion criteria were joined up to the study. The women (80) were divided into two groups: control group receiving routine hospital care and an experimental group practicing breathing exercise under the coaching of the researcher. Each group will comprise forty women. Three days per week during a period of five months

Results: study results illustrate no statistical significant difference between the control and experimental group in relation to socio-demographic and reproductive data as well as physiological stability, as evidenced by vital signs, during the study period. Also no statistical significant differentiation was found between the two studied groups in relation to their information and expectations about afterpains. Which guaranty homogeneity of the two studied groups, while there was a highly statically significant difference between the control and experimental groups in the favor of the breathing exercise.

Conclusions and recommendations: It was concluded from the study that practicing breathing exercise was effective in reduction of the mean score of afterpains among postpartum women. Researchers recommended; further studies are necessary in order to conclude a causal association between deep, slow breathing exercise and afterpains among postpartum women in different samples and settings.
\end{abstract}

Keywords: breathing exercise, afterpains, postpartum.

\section{Introduction}

Puerperium is a time when the mother is switching and adjusting to her new developmental role parallel to her social celebration of a new life, hence this critical phase is considered confusing to many women going through it especially for postpartum women $(1,2)$. Discomfort and after pains are a chief complain for mothers during their post partum period.

Immediately after the expulsion of the products of conception, the uterus begins the process of involution. During this process, the uterus normally contracts painlessly into a hard, firm, smooth, muscular mass approximately ten centimeters in diameter. On abdominal palpation the apex of the fundus can be felt at or slightly below the umbilicus. No change in the size of the uterus is noted for approximately two days, after which it rapidly diminishes in size and, within five to six weeks, regains its normal size (3-5).

During this involutional process, some women, experience painful uterine contractions which are commonly called afterpains (6). The pain has been described as pulling, tugging, cramping, sharp, or dull. The most severe discomfort produced from these painful uterine contractions seems to occur within the first 48 hours after delivery (7). No explanation of the cause or mechanism of uterine pains has been universally accepted. However, several predisposing mechanisms have been identified. Simultaneously, afterpains may be due to ischemia of the uterus as the result of uterine contractions (8).

According to Weidencach's PRESCRIPTIVE THEORY 1964 (9), nursing is the practice of identifying patient needs, determining the cause of discomfort and helping the patient to use her potentials to resolve discomfort where patient could be any one needs help not necessary ill. According to this theory the obstetric nursing practice is enhanced when gaining postpartum woman's cooperation to overcome afterpains through interventional practices including non-pharmacological methods of pain relief such as breathing exercise. Afterpains is one of the postpartum mother's immediate needs. However if the mother use her own efforts to relive it; she can do this without assistance latter on (10). It is a fact that intervention for pain and discomfort during labor and postpartum is a major part of modern obstetric care for laboring women and a challenging issue for nurses designing intervention protocols (11). Nurses, who care for women, must learn to 
understand, assess, and intervene with the postpartum pains and discomfort as both a sensory and affective phenomenon. These must be done according to the individual woman's needs and desires. In the fields of obstetric nursing and midwifery, the main professional goal has been to ensure a safe and optimal labor experience with minimal pain and discomfort. It was found that women with positive feelings about their labors and births recalled being well cared for and supported by health care personnel. Vice versa, women with negative feeling associated with childbirth recounted unpleasant and disappointing interactions with hospital staff (12). Within this context, nurses should never underestimate their ability to increase or diminish a woman's feelings of self-esteem, sense of accomplishment, and overall satisfaction with birth and strive to assist all clients with their transformation to parenthood.

\section{Significance of the study:}

One of the most crucial tasks of obstetric nurse is to support women during postpartum period. Efficient after pains' management is a critical part of obstetric nursing care to endorse postnatal recovery, it defiantly reduces anxiety and helps mother to cope with her new life and accomplish her family functioning. Non pharmacologic measures are often simple, secure, and reasonably priced method for pain relieve, extensively studied for labor pain. Yet postpartum after pains is still a neglected area of research. Breathing exercise is a non-pharmacological pain relieves measure that has been set up as effective for acute pain in situations other than after pains (13). But there is a lack of research evidence to support its effectiveness in relieving the after pains. Therefore this study was conducted to examine the effect of breathing exercise on afterpains for postpartum women.

\section{Aim of the Study}

The aim of this study is to determine the effect of breathing exercise on afterpains among postpartum women

\section{Operational Definition}

In the context of this study the breathing technique is; when feeling afterpains coming, the researcher instructs the postpartum woman to begin to focus on her breathing, and invite her body and mind to begin to relax. Take slow deep breath from nose, imagining the air flowing in to the very bottom and top of lungs, letting all areas of lungs expand with air and then fall while blowing air from mouth. Again return breathing to normal. $^{(1)}$

\section{Hypothesis}

The researchers hypothesized that postpartum mother who was trained on self-care method such as breathing exercise to relieve afterpains would have more tolerance and exhibit less pain and be able to efficiently utilize her potentials to maintain her comfort.

\section{Materials And Method}

\section{Materials}

\section{Research design:}

This is a quasi-experimental research design. Where the effect of breathing exercises (independent variable) on afterpains (dependent variable) will be examined

\section{Setting:}

This study will be conducted in postpartum unit of the Main Maternity University Hospital in Alexandria-Egypt. This setting was chosen because the turn over of deliveries is high.

\section{Subjects:}

The study subjects will be selected by using the non-probability sampling technique where a convenient sample of eighty postpartum women will be recruited. All subjects should meet the specified inclusion criteria. These criteria include:

- Do not receive any pharmacological pain relief substance.

- Full-term (37 to 42 weeks of gestation).

- Free from any medical or obstetric risk factors and/or conditions.

- Have a single viable fetus in cephalic presentation.

- Willing to participate in the study.

The women eighty will be assigned to one of two groups: a control group receiving routine hospital care and an experimental group practicing breathing exercise under the coaching of the researcher. Each group will comprise forty women. 
Tools:

Two tools will be used for data collection.

Tool I: Socio-demographic, reproductive and clinical data structured interview schedule

This tool will be developed and used by the researcher to collect the following data:

1. Socio-demographic characteristics including: age, occupation and level of education.

2. Menstrual history including: menarche, regularity and dysmenorrhea.

3. History of current labor: uterine contractions (duration, frequency, intensity and interval), rupture of membranes and presence of show.

4. Present complains in relation to afterpains: site and character of pain.

5. Women's information and expectations about afterpains.

6. Clinical data including physical assessment such as: vital signs, and fundal assessment.

\section{Tool II: Visual analog scale (VAS)}

It was developed by Melzack and Katz (1994); it is a self-report device consisting of a horizontal line used for subjective estimation of patient's pain. It comprises 10 point numerical scale, corresponding to the degree of pain with zero representing no pain and 10 representing the worst degree of pain. In between these two opposite ends, words as mild, moderate, severe and very severe pain are assigned to each $2 \mathrm{~cm}$ distance, respectively ${ }^{(14)}$.

\section{Method}

1. Official approval from the directors of data collections settings was secured through an official letter from the faculty of nursing Alexandria University after explanation of the purpose of the study

2. Tool (1) was developed by the researchers and reviewed for content validity by 9 faculty members from nursing and medicine faculties.

3. Tool (2) was tested for validity and reliability by other researchers.

4. Ethical considerations: for each recruited subject were considered as; each postpartum woman was individually contracted and informed about the aim of the study in order to obtain her written consent.

5. Again each of those who agree to participate was assured about their confidentiality, privacy and right to withdraw at any time.

6. A pilot study was carried out on 5 women to evaluate the clarity and applicability of tools and no modifications was done.

7. Three days per week were specified for data collection over a period of approximately five months from beginning of July to the end of December 2016.

8. Women were selected from the previously mentioned setting according to the inclusion criteria.

9. Each laboring woman in the two groups was individually interviewed o collect basic data using tool I.

10. Each woman was assigned to one of the tow study groups as follows:

a. The control group comprised of forty women; received the routine hospital care in addition to researcher's physical presence.

b. The experimental group comprised of forty women upon whom breathing exercise was demonstrated by the researcher and performed by the women throughout the early period of the postpartum.

11. The control group was started with and completed before starting the experimental group to avoid contamination of the sample

12. Pain states were evaluated for both experimental and control groups twice, once before and once after the period of intervention using tool II.

13. The effect of breathing exercise on postpartum afterpains was determined by comparing the mean score of pain intensity between the two groups before and after the intervention.

\section{Data Analysis}

SPSS software version 20 was used to analyze the data. Chi square (x2) test was significance at $\mathrm{p}$ value $<0.05$. Mean and standard deviation was considered for descriptive data. One sample t-test was used to examine whether there was any statistically significant difference between the control and the experimental (breathing exercise) group.

\section{Results}

Table (1) shows the distribution of the study groups according to their Socio-demographic data. Age demonstrated that around three quarters of the control and study group (80\% \& $70 \%)$ respectively were between the ages of 20 to 30 years old. Level of education revealed that $42.5 \%$ of the control group and $52.5 \%$ of the experimental group had secondary education. Residence elucidated that majority of both studied groups (70\% of the control group and $75 \%$ of the experimental group) were urban dwellers. In relation to occupation and marital 
status, all the control group and the experimental groups were housewives and married No statistical significant difference was found between the two groups in relation to the examined parameters.

Table (1): Distribution of the study groups according to their Socio-demographic data

\begin{tabular}{|c|c|c|c|c|c|}
\hline \multirow[t]{2}{*}{ Socio-demographic data } & \multicolumn{2}{|c|}{$\begin{array}{c}\text { Control group } \\
(\mathrm{No}=40)\end{array}$} & \multicolumn{2}{|c|}{$\begin{array}{l}\text { Experimental group } \\
\quad(\mathrm{No}=\mathbf{4 0})\end{array}$} & \multirow{2}{*}{$\begin{array}{c}\mathrm{X} 2 \& \\
\text { P value }\end{array}$} \\
\hline & No & $\%$ & No & $\%$ & \\
\hline \multicolumn{6}{|c|}{ Age (years) } \\
\hline$-\quad<20$ & 4 & 10 & 6 & 15 & \multirow{3}{*}{$\begin{array}{l}X 2=0.69 \\
P=0.706\end{array}$} \\
\hline - $20-30$ & 32 & 80 & 28 & 70 & \\
\hline$>30$ & 4 & 10 & 3 & 7.5 & \\
\hline \multicolumn{6}{|c|}{ level of education } \\
\hline Illiterate & 15 & 37.5 & 11 & 27.5 & \multirow{5}{*}{$\begin{array}{l}X 2=3.32 \\
P=0.505\end{array}$} \\
\hline Read and write & 4 & 10 & 2 & 5 & \\
\hline Primary/ preparatory & 2 & 5 & 5 & 12.5 & \\
\hline Secondary & 17 & 42.5 & 21 & 52.5 & \\
\hline - $\quad$ University & 2 & 5 & 1 & 2.5 & \\
\hline \multicolumn{6}{|c|}{ Residence } \\
\hline Urban & 28 & 70 & 30 & 75 & \multirow{2}{*}{$\begin{array}{l}X 2=0.25 \\
P=0.617\end{array}$} \\
\hline $\begin{array}{ll}- & \text { Rural }\end{array}$ & 12 & 30 & 10 & 10 & \\
\hline
\end{tabular}

Table (2) represents the distribution of the study groups according to their menstrual history. Itwas observed that the vast majority of the control and the experimental groups $(90 \% \& 85 \%)$ had their first menstruation between 12-15 years old. The Duration of menstruation for more than two fifths of both groups $(45 \%)$ ranged between 5-6 days. Majority of them $(85 \%$ \& $77.5 \%)$ respectively had a menstrual interval that ranged between 28-35 days. Most of women in the control group and the experimental group (90\% \& 92.5\%) respectively had regular menstruation. In relation to the amount of menstrual flow, more than two thirds $(72.5 \%$ $\& 67.5 \%$ ) respectively of both control and the experimental group mentioned that it was moderate. Moreover, most of both groups $(97.5 \% \& 92.5 \%)$ had history of dysmenorrhea among them more than half $(55 \%$ \& $62.5 \%$ ) correspondingly, mentioned that they "usually had dysmenorrheal". When women were asked about ways to overcome dysmenorrheal; "warm drinks" was stated by half of them $(55 \%$ of the control group and $52.5 \%$ of the experimental group). No statistical significant difference was found in relation to the examined parameters.

Table (2): Distribution of the study groups according to their menstrual history

\begin{tabular}{|c|c|c|c|c|c|c|}
\hline & \multirow[t]{2}{*}{ Menstrual history } & \multicolumn{2}{|c|}{$\begin{array}{l}\text { Control group } \\
(\mathrm{No}=40)\end{array}$} & \multicolumn{2}{|c|}{$\begin{array}{c}\text { Experimental group } \\
(\mathrm{No}=40)\end{array}$} & \multirow{2}{*}{$\begin{array}{c}\text { X2 \& } \\
\text { P value }\end{array}$} \\
\hline & & No & $\%$ & & $\%$ & \\
\hline \multicolumn{7}{|c|}{ Age at menarche (years) } \\
\hline- & $<12$ & 4 & $\mathbf{1 0}$ & 6 & 15 & \multirow{2}{*}{$\begin{array}{l}X 2=0.45 \\
P=0.499\end{array}$} \\
\hline- & $12-15$ & 36 & 90 & 34 & 85 & \\
\hline \multicolumn{7}{|c|}{ Duration of menstruation (days) } \\
\hline- & $3-4$ & 16 & 40 & 18 & 45 & \multirow{3}{*}{$\begin{array}{l}X 2=0.51 \\
P=0.772\end{array}$} \\
\hline- & 5- 6 & 18 & 45 & 18 & 45 & \\
\hline- & 7 & 6 & 15 & 4 & 10 & \\
\hline \multicolumn{7}{|c|}{ Interval between menstruation(days) } \\
\hline- & $<28$ & 4 & 10 & 5 & 12.5 & \multirow{3}{*}{$\begin{array}{l}X 2=0.92 \\
P=0.632\end{array}$} \\
\hline- & 28-35 & 34 & 85 & 31 & $\mathbf{7 7 . 5}$ & \\
\hline- & $>35$ & 2 & 5 & 4 & 10 & \\
\hline \multicolumn{7}{|c|}{ Rhythm } \\
\hline- & Regular & 36 & 90 & 37 & 92.5 & \multirow{2}{*}{$\begin{array}{l}X 2=0.16 \\
P=0.692\end{array}$} \\
\hline- & Irregular & 4 & 10 & 3 & 7.5 & \\
\hline \multicolumn{7}{|c|}{ Amount } \\
\hline- & Scanty & 1 & 2.5 & 1 & 2.5 & \multirow{3}{*}{$\begin{array}{l}X 2=0.25 \\
P=0.881\end{array}$} \\
\hline- & Moderate & 29 & 72.5 & 27 & 67.5 & \\
\hline- & Excessive & 10 & 25 & 12 & 30 & \\
\hline \multicolumn{7}{|c|}{ Dysmenorrhea } \\
\hline- & Yes & 39 & 97.5 & 37 & 92.5 & \multirow{2}{*}{$\begin{array}{c}X 2=1.05 \\
P=0.305\end{array}$} \\
\hline- & No & 1 & 2.5 & 3 & 7.5 & \\
\hline \multicolumn{7}{|c|}{ If yes: how often the woman feel dysmenorrhea } \\
\hline- & Usually & 22 & 55 & 25 & 62.5 & \multirow{4}{*}{$\begin{array}{c}X 2=2.08 \\
P=0.557\end{array}$} \\
\hline- & Sometimes & 8 & 20 & 6 & 15 & \\
\hline- & Often & 9 & 22.5 & 6 & 15 & \\
\hline- & Not Applicable & 1 & 2.5 & 3 & 7.5 & \\
\hline \multicolumn{7}{|c|}{ Pain intensity of dysmenorrhea } \\
\hline
\end{tabular}


Effect of breathing exercise on afterpains among postpartum women

\begin{tabular}{|c|c|c|c|c|c|c|}
\hline- & Mild & 7 & $\mathbf{1 7 . 5}$ & 6 & 15 & \multirow{4}{*}{$\begin{array}{l}X 2=1.43 \\
P=0.699\end{array}$} \\
\hline- & Moderate & 7 & $\mathbf{1 7 . 5}$ & 8 & 20 & \\
\hline - & Severe & 25 & 62.5 & 23 & 57.5 & \\
\hline - & Not applicable & 1 & 2.5 & 3 & 7.5 & \\
\hline \multicolumn{7}{|c|}{ Ways to overcome dysmenorrhea } \\
\hline - & Nothing & 10 & 25 & 8 & 20 & \multirow{4}{*}{$\begin{array}{l}X 2=1.31 \\
P=0.726\end{array}$} \\
\hline- & Analgesics & 7 & $\mathbf{1 7 . 5}$ & 8 & 20 & \\
\hline - & Warm drinks & 22 & 55 & 21 & 52.5 & \\
\hline- & Not applicable & 1 & 2.5 & 3 & 7.5 & \\
\hline
\end{tabular}

Table (3) clarifies the distribution of the study groups according to their reproductive data. It was observed that $75 \%$ \& $80 \%$ of the control and the experimental group respectively had two pregnancies and deliveries. Moreover, minority of both groups $(2.5 \% \& 7.5 \%)$ in that order had suffered from previous abortion.

Table (3): Distribution of the study groups according to their reproductive data

\begin{tabular}{|c|c|c|c|c|c|c|}
\hline & \multirow[t]{2}{*}{ Reproductive history } & \multicolumn{2}{|c|}{$\begin{array}{c}\text { Control group } \\
(\mathrm{No}=40)\end{array}$} & \multicolumn{2}{|c|}{$\begin{array}{c}\text { Experimental group } \\
(\mathrm{No}=40)\end{array}$} & \multirow[t]{2}{*}{$\begin{array}{c}\text { X2 \& } \\
\text { P value }\end{array}$} \\
\hline & & No & $\%$ & No & $\%$ & \\
\hline \multicolumn{7}{|c|}{ Gravidity } \\
\hline - & 2 & 30 & 75 & 32 & 80 & \multirow{3}{*}{$\begin{array}{l}X 2=1.44 \\
P=0.486\end{array}$} \\
\hline- & 3 & 5 & 12.5 & 6 & 15 & \\
\hline- & $4+$ & 5 & 12.5 & 2 & 5 & \\
\hline \multicolumn{7}{|c|}{ Parity } \\
\hline - & 1,2 & 30 & 75 & 32 & 80 & \multirow{4}{*}{$\begin{array}{c}X 2=3.73 \\
P=0.292\end{array}$} \\
\hline- & 3 & 4 & 10 & 4 & 10 & \\
\hline- & $4+$ & 5 & 12.5 & 1 & 2.5 & \\
\hline- & Not applicable & 1 & 2.5 & 3 & 7.5 & \\
\hline \multicolumn{7}{|c|}{ Abortion } \\
\hline- & No abortion & 39 & 97.5 & 37 & 92.5 & \multirow{2}{*}{$\begin{array}{l}X 2=1.052 \\
P=0.305\end{array}$} \\
\hline- & 1 & 1 & 2.5 & 3 & 7.5 & \\
\hline
\end{tabular}

Figure (1) exhibits the distribution of the study groups according to their weeks of gestation. It was found that around one third $(37.5 \%$ of the control group \& $30 \%$ of the experimental group) were full-term (38weeks), with no statistical difference between the two groups.

Figure (1): Distribution of the study groups according to their history of current pregnancy

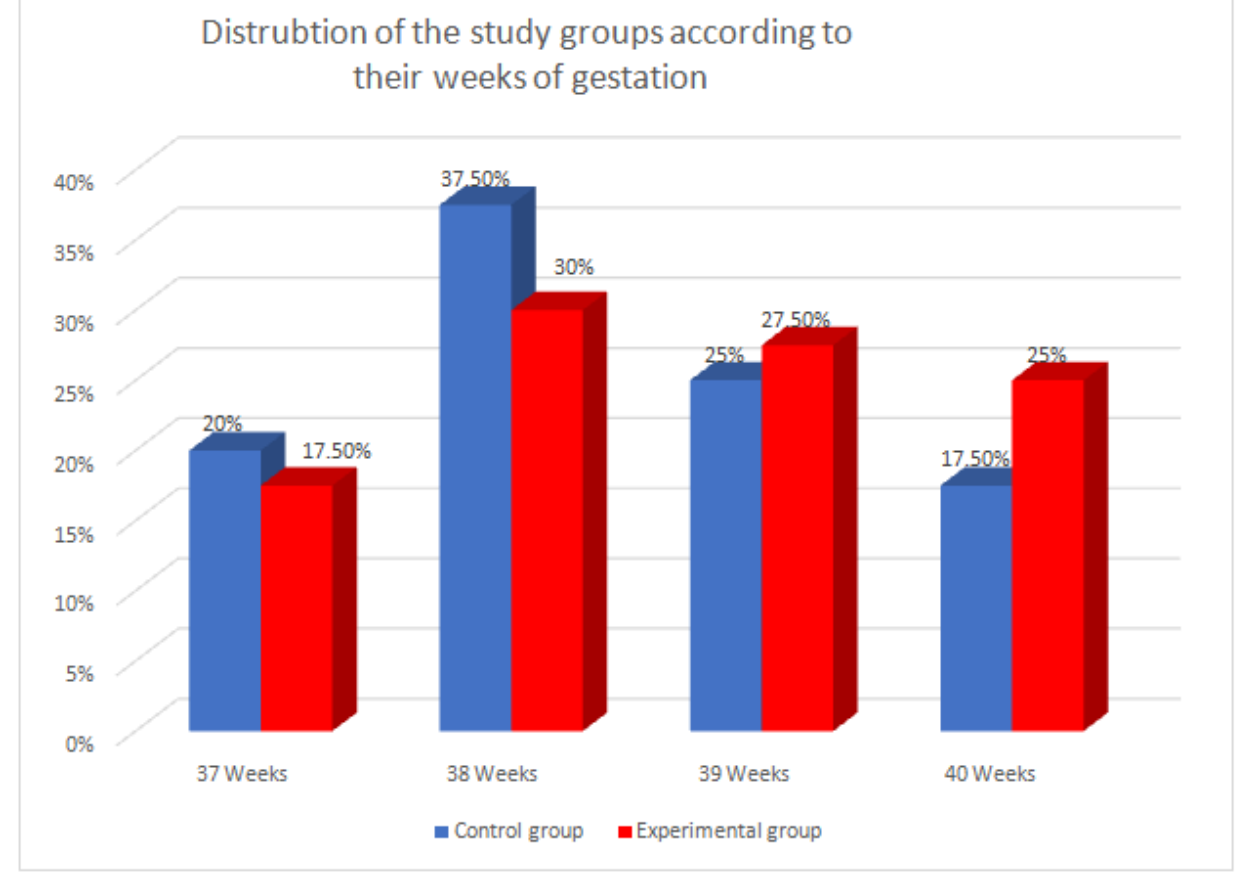


Table (4) presents the distribution of the study groups according to their mean vital signs. In general all women in both study groups were physiologically stable with normal vital signs. As regard to pulse, it was observed that the control group had the same pattern of pulse rate as the experimental group (70.7142 \pm 5.0099 $\mathrm{b} / \mathrm{m} \& 70 \pm 5.0636 \mathrm{~b} / \mathrm{m}$ ) respectively. In relation to systolic blood pressure, the table shows that the control group mean systolic blood pressure was $(111 \pm 4.9613) \mathrm{mmHg}$ while it was $(109 \pm 4.9613) \mathrm{mmHg}$ among the experimental group. On the other hand, the diastolic blood pressure was nearly the same mean $(72 \pm 4.6409 \&$ $72.5 \pm 4.3852) \mathrm{mmHg}$ among the control and experimental group respectively. Regard respiration, it was noticed that mean respiratory rate of the control group was $21.85 \pm 3.5268 \mathrm{c} / \mathrm{m}$ and $22.725 \pm 3.3203 \mathrm{c} / \mathrm{m}$ for the experimental group. The table also shows that the mean temperature was $37.175 \pm 0.1808 \& 37.2 \pm 0.1519$ among the control group and the experimental group respectively without statistical significant difference between them in relation to vital signs.

Table (4): Distribution of the study groups according to their mean vital sigs

\begin{tabular}{|c|c|c|c|}
\hline \multirow[t]{2}{*}{ Vital signs } & $\begin{array}{l}\text { Control group } \\
(\mathrm{No}=\mathbf{4 0})\end{array}$ & $\begin{array}{l}\text { Experimental group } \\
(\mathrm{No}=40)\end{array}$ & \multirow{2}{*}{$\begin{array}{c}\text { X2 \& } \\
\text { P value }\end{array}$} \\
\hline & No & No & \\
\hline \multicolumn{4}{|c|}{ Pulse } \\
\hline MEAN \pm SD & $70.7142 \pm 5.0099$ & $70 \pm \quad 5.0636$ & $\begin{aligned} t & =0.63 \\
P & =0.528\end{aligned}$ \\
\hline \multicolumn{4}{|c|}{ Systolic blood pressure } \\
\hline - MEAN \pm SD & $111 \pm 4.9613$ & $109 \pm \quad 4.9613$ & $\begin{aligned} t & =1.80 \\
P & =0.075\end{aligned}$ \\
\hline \multicolumn{4}{|c|}{ Diastolic blood pressure } \\
\hline - MEAN \pm SD & 4.6409 & $72.5 \pm 4.3852$ & $\begin{array}{c}t=0.50 \\
P=0.622\end{array}$ \\
\hline \multicolumn{4}{|c|}{ Respiration } \\
\hline MEAN \pm SD & $21.85 \pm 3.5268$ & $22.725 \pm \quad 3.3203$ & $\begin{aligned} t & =1.14 \\
P & =0.257\end{aligned}$ \\
\hline \multicolumn{4}{|c|}{ Temperature } \\
\hline MEAN \pm SD & $37.175 \pm 0.1808$ & $37.2 \pm 0.1519$ & $\begin{aligned} t & =0.67 \\
P & =0.505\end{aligned}$ \\
\hline
\end{tabular}

Table (5) demonstrates distribution of the study groups according to their information and expectations about afterpains. Three quarters of the control group (75\%) and $80 \%$ of the experimental group was not able to define afterpains or its duration, as well as they had no expectation about afterpains whether it will be mild, moderate or severe. Also the table shows that the vast majority of both groups $(95 \% \& 97.5 \%)$ didn't know the predisposing factors for afterpains. No statistical significant difference was found in relation to the examined considerations.

Table (5): Distribution of the study groups according to women's information and expectations about afterpains:

\begin{tabular}{|c|c|c|c|c|c|}
\hline \multirow[t]{2}{*}{$\begin{array}{c}\text { women's information about } \\
\text { after pain }\end{array}$} & \multicolumn{2}{|c|}{$\begin{array}{l}\text { Control group } \\
(\mathrm{No}=40)\end{array}$} & \multicolumn{2}{|c|}{$\begin{array}{c}\text { Experimental group } \\
(\mathrm{No}=\mathbf{4 0})\end{array}$} & \multirow{2}{*}{$\begin{array}{c}\text { X2 \& } \\
\text { P value }\end{array}$} \\
\hline & No & $\%$ & No & $\%$ & \\
\hline \multicolumn{6}{|c|}{ Define afterpains } \\
\hline Know & 10 & 25 & 8 & 20 & \multirow{2}{*}{$\begin{array}{c}X 2=0.29 \\
P=.592\end{array}$} \\
\hline Do not know & 30 & 75 & 32 & 80 & \\
\hline \multicolumn{6}{|c|}{ Duration of afterpains } \\
\hline Less than one day & 2 & 5 & 2 & 5 & \multirow{3}{*}{$\begin{array}{c}X 2=0.35 \\
P=.839\end{array}$} \\
\hline More than one day & 8 & 20 & 6 & 15 & \\
\hline Do not know & 30 & 75 & 32 & 80 & \\
\hline \multicolumn{6}{|c|}{ Predisposing factors of afterpains } \\
\hline Breast feeding & 2 & 5 & 1 & 2.5 & \multirow{3}{*}{$\begin{array}{c}X 2=0.35 \\
P=.841\end{array}$} \\
\hline Full bladder & - & - & - & - & \\
\hline Do not know & 38 & 95 & 39 & 97.5 & \\
\hline \multicolumn{6}{|c|}{ Women expectation about afterpains } \\
\hline Mild & 1 & 2.5 & 1 & 2.5 & \multirow{4}{*}{$\begin{array}{c}X 2=0.73 \\
P=.866\end{array}$} \\
\hline Moderate & 4 & 10 & 2 & 5 & \\
\hline Severe & 5 & 12.5 & 5 & 12.5 & \\
\hline Do not know & 30 & 75 & 32 & 80 & \\
\hline
\end{tabular}

Table (6) shows the distribution of the study groups according to the intensity of their afterpain as measured by visual analogue scale (VAS) before and after breathing exercises. More than two fifth (45\%) of the control group had moderate pain before routine hospital care compared to more than three fifth $(67 \%)$ of the same group after routine hospital care while approximately one third $(32.5 \%)$ of the experimental group suffered 
from moderate pain before the breathing exercise compared to around one fifth $(22.5 \%)$ after the intervention. A statistical significant difference was noticed among women of the control group before and after routine hospital care where $\mathrm{P}=0.0352$, it's a pity that the difference was to the favor of the increased pain intensity for this group. Vise versa the statistical difference for the experimental group shows decreased pain intensity after breathing exercise than before the practice where $\mathrm{P}=0.0256$.

Table (6): Distribution of the study groups according to the intensity of their afterpain (as measured by visual analogue scale (VAS) before and after breathing exercises

\begin{tabular}{|c|c|c|c|c|c|c|c|c|}
\hline \multirow{3}{*}{$\begin{array}{l}\text { Intensity of labor pain } \\
\text { as measured by (VAS) }\end{array}$} & \multicolumn{4}{|c|}{$\begin{array}{c}\text { Control group } \\
(\mathrm{No}=40)\end{array}$} & \multicolumn{4}{|c|}{$\begin{array}{c}\text { Experimental group } \\
(\mathrm{No}=40)\end{array}$} \\
\hline & \multicolumn{2}{|c|}{$\begin{array}{l}\text { Before routine } \\
\text { hospital care }\end{array}$} & \multicolumn{2}{|c|}{$\begin{array}{c}\text { After routine hospital } \\
\text { care } \\
(\mathbf{3 0} \mathrm{min})\end{array}$} & \multicolumn{2}{|c|}{$\begin{array}{l}\text { Before breathing } \\
\text { exercise }\end{array}$} & \multicolumn{2}{|c|}{$\begin{array}{l}\text { After breathing exercise } \\
(30 \mathrm{~min})\end{array}$} \\
\hline & No & $\%$ & No & $\%$ & No & $\%$ & No & $\%$ \\
\hline $\begin{array}{l}\text { No pain } \\
\text { (zero) }\end{array}$ & - & - & - & - & - & - & 5 & 12.5 \\
\hline $\begin{array}{c}\text { Mild } \\
\text { (From } 1 \text { to } 3 \text { points) }\end{array}$ & 20 & 50 & 10 & 25 & 25 & 62.5 & 26 & 65 \\
\hline $\begin{array}{c}. \text { Moderate } \\
\text { (From } 4 \text { to } 6 \text { points) }\end{array}$ & 18 & 45 & 27 & 67.5 & 13 & 32.5 & 9 & 22.5 \\
\hline $\begin{array}{c}\text { Severe } \\
\text { (From } 7 \text { to } 9 \text { points) }\end{array}$ & 2 & 5 & 3 & 7.5 & 2 & 5 & 0 & 0 \\
\hline $\begin{array}{l}\text { unbearable } \\
\text { (10 points })\end{array}$ & - & - & - & - & - & - & - & - \\
\hline Mean \pm SD & \multicolumn{2}{|c|}{$3.65 \pm 1.791$} & \multicolumn{2}{|c|}{$\frac{1}{4.48 \pm 1.6484}$} & \multicolumn{2}{|c|}{$3.28 \pm 1.7829$} & \multicolumn{2}{|c|}{$\frac{1}{2.43 \pm 1.5506}$} \\
\hline T. test & \multicolumn{4}{|c|}{2.1438} & \multicolumn{4}{|c|}{2.2752} \\
\hline *P. value & \multicolumn{4}{|c|}{0.0352} & \multicolumn{4}{|c|}{0.0256} \\
\hline
\end{tabular}

*Statistical significant

Figure (2) compares the study groups according to their mean afterpains intensity. It was clear that the pain intensity score was 3.65 among the control group before routine hospital care increased to 4.48 after routine hospital care. On the other hand, it was 3.28 among the experimental group before breathing exercise decreased to 2.43 after breathing exercise. There was a highly statistically significant difference found between the two groups after the interventions where $\mathrm{p}$ is less than 0.0001

Figure (2): The distribution of the study groups according to their mean afterpains intensity.

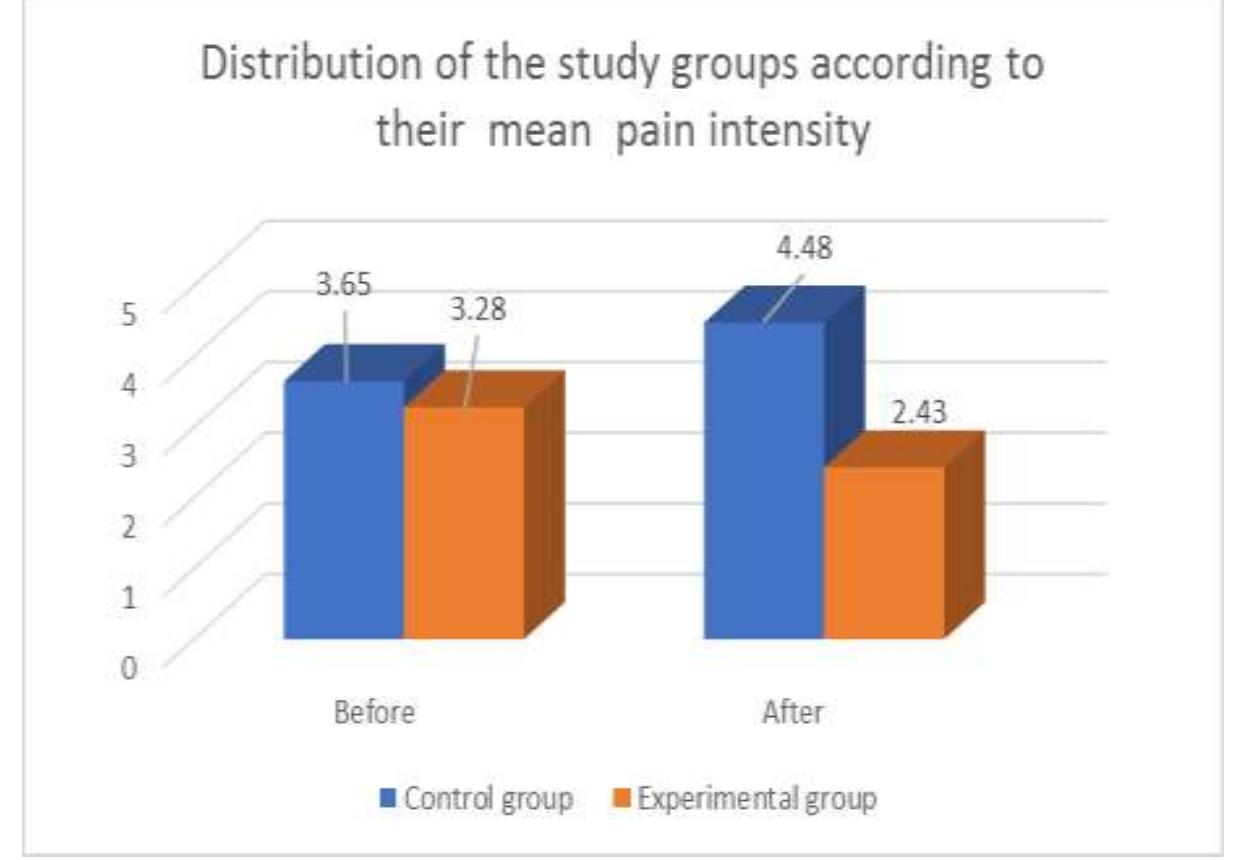

T. test $=5.7290 *$ P. value $<$ than 0.0001

*Statistical significant 


\section{Discussion}

Eighty postpartum women, meeting the inclusion criteria were enrolled to the study sample. Out of which forty women were assigned to the control group where routine hospital care was applied for them and the other forty practiced controlled breathing exercise during their afterpains. In general, study results illustrate no statistical significant difference between the control and experimental group in relation to socio-demographic and reproductive data as well as physiological stability, as evidenced by vital signs, during the study period. Also no statistical significant differentiation was found between the two studied groups in relation to their information and expectations about afterpains. Which guaranty homogeneity of the two studied groups. On the other hand, there was a highly statically significant difference between the control and experimental group in relation to afterpains, where the experimental group exhibited decreased mean score of afterpains than the control group.

This study exemplifies that women in both groups had no information or expectations about their afterpains. The researchers attribute that result to the fact that all women are concerned about labor pain imagining that it will be end with the delivery of fetus without any idea that postpartum period is a significant phase of birth process, with many physical and psychological changes. Congruent with the current finding; Gibson E, 2014 (15) had mentioned that, women were concerned with the pain of childbirth before and after their labor experiences. Another explanation of this result that most of counseling given during pregnancy emphasis on helping the woman to plan and prepare for birth, neglecting health education about puerperium except breast feeding (16)

The principal finding in this study is that postpartum women practiced breathing exercise reported significantly less afterpains than women without that breathing implementation. Consequently, the breathing exercise, with the approach utilized, would presumably be acceptable in this population to increase pain tolerance. This result is congruent with the fact that breathing thought to be efficient in pain relieve because it diverts, a focus away from the pain. Breathing together with relaxation reduced pain perception (17). Furthermore, Lothian 2010 (18), supported the current finding as it was mentioned that conscious breathing and relaxation are important as well as evidence-based approaches to handle pain (as postpartum afterpains) not because it is a distraction only but also because controlled breathing, particularly slow, deep breathing, enhances oxygenation, relaxation, and body awareness. Focusing on breathing and relaxing blocks out other distractions and helps woman becomes more aware, more attentive, more alert, and more focused.

Unfortunately, similar research studies to the present study, investigating the effect of breathing exercise on postpartum after pains are exceptional. But this study was similar to another findings conducted but for laboring women indicating a significance difference between the mean pain scores of experimental group than control group which shows that the slow paced breathing initiated by the investigator was effective in reduction of pain during the first stage of labor $(19,20,21)$.

There were several breathing patterns and strict guidelines for "doing it right" but the "right" way to breathe is whatever feels right (22). Researchers go further as they assumed that; there are no rules related to the count of breaths per minute, or whether to make sounds with inhalation or not. The key here is that the breathing is deep taken from nose slowly exhaled from mouth, conscious and not automatic. Just slow, deep breathing is particularly effective. Fortunately this makes breathing as a simply issue during afterpains, easy to learn for postpartum women.

The researchers' hypothesis is derived from the gate-control theory of pain. It is a pain theory used to explain the neurophysiologic mechanism underlying the perception of pain: the capacity of nerve pathways to transmit pain is reduced or completely shut by using distraction techniques (23). The researches in the present study presumed controlled breathing as one of those destructions techniques.

Moreover, scientists had mentioned that using deep controlled breathing in everyday life, either to relieve stress or to increase body awareness and mindfulness, is excellent practice. It is an excellent life skill (24). Since, besides deep breathing activates the release of endorphins, which improves feelings of wellbeing and provides pain-relief (25); breathing exercises precisely have many benefits. When to take deep, slow breaths, body responds in many positive ways: muscles relax, as it's difficult to maintain a lot of physical tension when breathing properly (26). When breathe deeply and relaxed, oxygen delivery improves, fresh oxygen pours into every cell in the body. This increases the functionality of every system in the body. It will also be noticed improved mental concentration and physical strength (27). Another valuable advantage of deep breathing is that it lowers blood pressure, as muscles relax, blood vessels dilate and its measurements can return back to a normal level. At last but not the least, good breathing habits help the lymphatic system function properly; this encourages the clearness of harmful toxins and allows it to direct its energy to more productive functions (28). Generally, available studies have confirmed the effect of breathing exercises on anxiety relief among mothers $(21,29)$. However, the researchers in the current study resulted to its significant effect on increased tolerance of mothers and reduction of postpartum afterpains. 


\section{Conclusion}

It was concluded from the statistical tests that practicing breathing exercise was effective in reduction of the mean score of afterpains among postpartum women. Analysis of data showed that there was a significant difference between the intervention and non intervention group. Breathing exercise is the effective, simple and non-invasive method of choice to be used for those women.

\section{Recommendations}

- The breathing exercise which was taught and which was administered to the postpartum women; encouraged them to have more tolerance and reduced their mean score of afterpains.

- Further studies are necessary in order to conclude a causal association between deep, slow breathing exercise and afterpains among postpartum women in different samples and settings.

\section{References}

[1]. Kathleen M. Pape. Mothering and the functional self: A Hermeneutic explanation of texts on perinatal mode and anxiety disorders. A dissertation for doctoral degree. Antioch University Seattle, Seattle, WA. November 2014.

[2]. Committee Opinion No. 666: Optimizing Postpartum Care. Obstet Gynecol. 2016 Jun. 127 (6):e187-92. [Medline].

[3]. DC Dutta \& Hiralal Konar. DC Dutta's Textbook of Obstetrics. $8^{\text {th }}$ edition. JAYPEE brothers medical publisher (P) LTD. London. 2015.

[4]. Murray, S., \& McKinney, E. Foundations of Maternal-Newborn and Women's Health Nursing. Postpartum Physiologic Adaptations CHAPTER 17. 6th ed.Maryland Heights: Saunders Elsevier. USA. 2014

[5]. Coutin, A. Essential obstetric and newborn care: practical guide for midwives, doctors with obstetric training and health care personnel who deal with obstetric emergencies. Medecins Sans Frontieres. Germany. 2015.

[6]. Deussen AR, Ashwood P, Martis R. Analgesia for relief of pain due to uterine cramping/involution after birth. Cochrane Database of Systematic Reviews 2011, 5. Alan H. DeCherney, Lauren Nathan, Neri Laufer, Ashley S. Roman. Current Diagnosis \& Treatment: Obstetrics \& Gynecology. Caroline Pessel; Ming C. Tsai. Chapter 10. The Normal Puerperium. 11edition. McGraw-Hill companies. USA. 2013.

[7]. Stergios K. Doumouchtsis Arulkumaran. Emergencies in Obstetrics and Gynaecology. $2^{\text {nd }}$. edition. The Oxford university press. USA. 2016

[8]. Melies, A. theoretical nursing developmental and progress. $5^{\text {th }}$ edition. Lippincott Williams \& Wilkins. China. 2012. Pp. 267-271.

[9]. Cashion K. Pain Management. In: Adaptive Learning for Maternal Child Nursing Care, 5th, Perry SE, Hockenberry MJ, Lowderrmilk DL, Wilson D. (Eds), Elsevier, Maryland Heights, MO 2014.

[10]. Lally E. J., Thomson G. R., MacPhail S. \& Exley C. Pain relief in labour: a qualitative study to determine how to support women to make decisions about pain relief in labour BMC Pregnancy and Childbirth201414:6 DOI: 10.1186/1471-2393-14-6

[11]. Karlström A., NystedtA., and Hildingsson I. The meaning of a very positive birth experience: focus groups discussions with women. BMC Pregnancy Childbirth. 2015; 15: 251.

[12]. Gabor B. Racz and Carl E. Noe, Pain Management - Current Issues and Opinions in Yurdanur Demir, Non pharmacological therapies in pain management chapter 23. InTech, USA. 2012. $485-502$

[13]. Marcel Dijkers. Comparing Quantification of Pain Severity by Verbal Rating and Numeric Rating Scales. J Spinal Cord Med. 2010 Jun; 33(3): 232-242.

[14]. Judith A. Lothian. Lamaze Breathing: What Every Pregnant Woman Needs to Know. J Perinat Educ. 2011 Spring; $20(2)$ : 118-120.

[15]. Gibson E. Women's expectations and experiences with labour pain in medical and midwifery models of birth in the United States. Women Birth. 2014 Sep;27(3):185-9.

[16]. Australian Health Ministers' Advisory Council 2012, Clinical Practice Guidelines: Antenatal Care - Module

[17]. Lothian J. A., DeVries C. The official Lamaze guide: Giving birth with confidence. 2nd ed. Minnetonka, MN: Meadowbrook Press; 2010.

[18]. Alden K, Perry E, Lowdermilk D. Maternity \& Women's Health Care, Lowdermilk D. chapter 12: Management of Discomfort. 11 Edition. Elsevier - Health Sciences Division, USA. 2015.

[19]. Sruthi L. effectiveness of breathing exercise on labor pain among primi mothers at selected hospital in Mangalore. Dissertation Submitted to Rajiv Gandhi University of Health Sciences, Bangalore, Karnataka In partial fulfillment of the requirements for the degree of Master of Science in Obstetrics and Gynecological Nursing. 2013

[20]. Nilima R.Bhore. a study to assess the effectiveness of selected aspects of Lamaze methods on pain among primigravida mothers during first stage of labor in selected hospital of Sangli. International Journal of Recent Scientific Research 2016.7 (10): 1354713550 .

[21]. Dengsangluri and Jyoti A Salunkhe. Effect of Breathing Exercise in Reduction of Pain during First Stage of Labour among Primigravidas. International Journal of Health Sciences \& Research. 2015; 5 (6): 390 - 398.

[22]. Barbara A. Hotelling. Continuing Education Module Styles Vary When Teaching Expectant Parents About Medications. J Perinat Educ. 2012 Winter; 21(1): 48-51.

[23]. Mike Thomas, Anne Bruton. Breathing exercises for asthma. Breathe journal. 2014, 10 (4): 312-322.

[24]. George Grant. Beta Endorphins \& Wellness. Global Journal of Addiction \& Rehabilitation Medicine. 2017,1 (3): 1.

[25]. Katayon Vakilian, Afsaneh Keramat. The Effect of the Breathing Technique With and Without Aromatherapy on the Length of the Active Phase and Second Stage of Labor. Nursing and Midwifery Studies. 2013:1(3) 115-119.

[26]. Siswantoyo, Mohd. Saleh Aman. The Effects of Breathing Exercise Toward IgG, Beta Endorphin and Blood Glucose Secretion. Asia Pacific Journal of Education, Arts and Sciences. September 2014, 1 (4): 27-32.

[27]. Dee Unglaub Silverthorn. Human Physiology: An Integrated Approach. $7^{\text {th }}$ edition. Pearson; USA. 2015

[28]. Valerie J. The Detox your heart: medications for healing emotional trauma. Wisdom publications. USA, 2017.

[29]. Mahin Kamalifard, Mahnaz Shahnazi, Manizheh Sayyah Melli, Shirin Allahverdizadeh, Shiva Toraby and Atefeh Ghahvechi. The Efficacy of Massage Therapy and Breathing Techniques on Pain Intensity and Physiological Responses to Labor Pain. J Caring Sci. 2012 Jun; 1(2): 73-78. 